University of Nebraska - Lincoln

DigitalCommons@University of Nebraska - Lincoln

Space, Cyber, and Telecommunications Law

Program Faculty Publications

Law, College of

2002

\title{
United Nations Principles on Remote Sensing and the User
}

Frans von der Dunk

University of Nebraska - Lincoln, fvonderdunk2@unl.edu

Follow this and additional works at: https://digitalcommons.unl.edu/spacelaw

Part of the Air and Space Law Commons

von der Dunk, Frans, "United Nations Principles on Remote Sensing and the User" (2002). Space, Cyber, and Telecommunications Law Program Faculty Publications. 17.

https://digitalcommons.unl.edu/spacelaw/17

This Article is brought to you for free and open access by the Law, College of at DigitalCommons@University of Nebraska - Lincoln. It has been accepted for inclusion in Space, Cyber, and Telecommunications Law Program Faculty Publications by an authorized administrator of DigitalCommons@University of Nebraska - Lincoln. 
Published (as Chapter 4) in Earth Observation Data Policy and Europe, edited by Ray Harris (Lisse: A. A. Balkema, 2002), pp. 29-40. Copyright ( 2002 Swets \& Zeitlinger B.V. (Division of Taylor \& Francis). Used by permission.

\title{
United Nations Principles on Remote Sensing and the User
}

\author{
Frans von der Dunk \\ International Institute of Air and Space Law, Leiden University, The Netherlands
}

\begin{abstract}
The United Nations Principles on Remote Sensing were adopted by consensus on 3 December 1986. They provide a set of non-binding yet agreed and politically relevant principles to guide the activities of remote sensing by the United Nations member states. The 15 principles are each examined in turn in this chapter.
\end{abstract}

\section{Introduction}

The United Nations (UN) Resolution Relating to Remote Sensing of the Earth from Outer Space was adopted by consensus on 3 December 1986, which implies that no single state entertained fundamental objections to its content. Especially in the absence of other (binding) instruments regulating the same subject matter, United Nations Resolutions can carry great moral and political weight, as well as nascent legal validity (so-called "soft law" status). Therefore, and in view of their general nature, the legal status of the principles is similar to that of general principles of international law. Indeed, important players in the remote sensing field such as ESA and NOAA made substantial efforts to adhere to the principles contained in the Resolution.

On the other hand. Resolutions of the United Nations General Assembly as such are not binding upon states, even upon those having voted in favor or consented. General principles, moreover, do not readily allow for clear-cut application without further ado. In the final analysis, only those principles that reflect already existing customary legal rules - and to the extent that they do not conflict among themselves - might be effectively binding upon states.

\section{The Resolution and the User: General Remarks}

This chapter deals with the Resolution on remote sensing and its impact on the user and user-relevant issues in an area involving a complex chain of activities with the resulting (legal) relations. While many types of users may be envisaged or are already active in the field, for the present purpose the user could perhaps best be circumscribed with reference 
to the chain of activities involved in satellite remote sensing, as being at the (receiving) end of that chain. Users can be public, private or mixed entities. From a future-oriented perspective, however, the private character of many users provides the most interesting feature, bringing the pertinent legal issues to the fore most clearly.

Usage can arise for a number of reasons, varying from commercial to scientific or military applications. From a practical - read user's - point of view it should be recalled that the major development in this field in recent years concerns remote sensing satellites which have very high resolution (VHR) capabilities, formerly the exclusive domain of the military. Since the end of the Cold War very high resolution data have become available on the civil market and for commercial purposes. Vice versa, it may become feasible to restrict the commercial use of such data precisely for reasons of national security. Either way, the inherent tendency of military activities to take place outside the reach of international regulation has to be noted.

Furthermore, with a view to user interests and issues, the two possible approaches to exercise legal control over data dissemination, and thereby indirectly usage, have to be kept in mind. On the one hand, individual states (and to the relevant extent the partly supranational European Community) are empowered to determine the legal parameters for data dissemination and use within their respective territory. Obviously, this also includes their "own" governmental activities, such as in the case of the United States the activities of NOAA.

On the other hand, a few entities, including international organizations (most notably ESA and EUMETSAT) are comprehensively involved in the activities of remote sensing itself. They have the power, through their ownership of the hardware involved and their intellectual ownership of the activities concerned as well as the results thereof, to determine at least what happens to such results downstream. This is achieved through contracts, rather than by legislation; and in the case of disseminators which are one or more steps further downstream, by a chain of contracts each incorporating and "trickling down" the relevant provisions. The net result is the same, however: the users of such data are at the receiving end of any such downstream contractual arrangement.

The UN Resolution focuses in the first instance on the space-related part of remote sensing operations, such as tracking-and-control activities with respect to the physical movements of the satellite, command activities regarding the remote sensing itself, and the transfer of data, live or by relay, to receiving stations on Earth. In addition, some terrestrial activities of great and direct importance for space operations have been involved and are included in the legal framework (to be) provided by the Resolution. This largely concerns activities with regard to treatment of the data in ground stations and thereafter.

However, in view of the user being the last element in the chain, the overriding consequence of this situation is that the UN Resolution plays its role in the area of defining parameters which have to be accepted more or less as given by any user. This applies also to those users not being the last element in the chain, acting as resellers or retailers. The only exceptions apply where a user is in the position either to take part also in operations upstream (e.g. a remote sensing operator simultaneously qualifying as reseller, retailer or user) or to also take part in regulatory activities upstream (e.g. an individual state as user).

A final point of note for user issues is the public law nature of the UN Resolution, as following from the general structure of international space law. To the extent that the principles under consideration would provide for (existing or nascent) legal rights and obligations thereof, this would be of direct concern to states only. They would be held responsible as well as liable on the international level for activities of private users in perti- 
nent cases. The (obvious) way for individual states to take care of such largely prospective international responsibility and liability for private user activities would be the establishment of national space legislation, specifically including licensing systems, in order to exercise the requisite legal control over such activities.

\section{The UN Principles}

This section reviews and comments upon each of the 15 UN Principles on Remote Sensing. The Principles are included in the text and can also be found in Appendix C.

\subsection{Principle I}

For the purposes of these principles with respect to remote sensing activities:

(a) The term "remote sensing" means the sensing of the Earth's surface from space by making use of the properties of electromagnetic waves emitted, reflected or diffracted by the sensed objects, for the purpose of improving natural resources management, land use and the protection of the environment;

(b) The term "primary data" means the raw data that are acquired by remote sensors borne by a space object and that are transmitted or delivered to the ground from space by telemetry in the form of electromagnetic signals, by photographic film, magnetic tape or any other means;

(c) The term "processed data" means the products resulting from the processing of the primary data, needed to make such data usable;

(d) The term "analyzed information" means the information resulting from the interpretation of processed data, inputs of data and knowledge from other sources;

(e) The term "remote sensing activities" means the operation of remote sensing space systems, primary data collection and storage stations, and activities in processing, interpreting and disseminating the processed data.

Firstly, it may be noted that the UN Resolution applies to remote sensing activities "for the purpose of improving natural resources management, land use and the protection of the environment." Since such usage arguably would not require quality of spatial resolution better than in the range of 10 meters, any VHR issues might fall outside the scope of the Resolution. In other words: the Resolution would seem to leave the individual discretion of states, European Union and international operational remote sensing organizations intact as to how to deal for example with dissemination and usage issues regarding VHR data. Privacy aspects of VHR remote sensing data dissemination, at least, have not been considered.

Another issue following from this, somewhat narrow, definition of remote sensing for the purposes of the Resolution, is that it might be taken to exclude from its scope any military activities. This, however, is of relatively little importance, since few of the other Principles contained in the Resolution could carry legal force as well as practical weight when it comes to military and security-related remote sensing activities.

Secondly, the threefold distinction of primary data, processed data, and analyzed information is noteworthy. Whether or not this distinction makes sense from a practical 
and/or particular user's point of view, it obviously has a legal impact. The core activity of creating primary data takes place in outer space, whereas the processing and analyzing which defines the two other categories are primarily terrestrial activities (at least so far).

Individual states would, to say the least, be strongly stimulated to use this distinction also in any national regulation of remote sensing activities. Practice shows, however, that this is certainly not always the case. For example in the United States within national acts on remote sensing ${ }^{1}$ the crucial distinction is made between unenhanced data and valueadded data, which is not exactly the same as that between primary data and processed data, whereas "analyzed information" does not figure as such at all in the acts.

Thirdly, further to the functional scope of the Resolution, subparagraph (e) again makes clear that the Resolution does not restrict itself purely to the space activities involved. Most importantly, the dissemination of processed data, an area of obvious prominence for user issues, is directly subject to the principles contained in the Resolution.

\subsection{Principle II}

Remote sensing activities shall be carried out for the benefit and in the interests of all countries, irrespective of their degree of economic, social or scientific and technological development, and taking into particular consideration the needs of the developing countries.

The very general reference to "the benefit and [...] interests of all countries" with special consideration for the developing countries is of considerable preponderance in international space law treaties and resolutions. In 1996, a United Nations Resolution ${ }^{2}$ specifically dealing with further interpretation and elaboration of this concept, however, left complete freedom to states "to determine all aspects" of such cooperation, further repeatedly referring to the requirement of "an equitable and mutually acceptable basis" for any activities undertaken in its implementation.

The concept therefore at present has little direct relevance for user issues. This would only change if individual states were to draw substantive conclusions from this provision, and domestically implement regulations substantiating vis-à-vis disseminators and/ or users the benefit and interest of all or specifically the developing countries.

\subsection{Principle III}

Remote sensing activities shall be conducted in accordance with international law, including the Charter of the United Nations, the Treaty on Principles Governing the Activities of States

1 Land Remote Sensing Commercialization Act, Public Law 98-365, 98th Congress, H.R. 5155, 17 July 1984; 98 Stat. 451; Space Law - Basic Legal Documents, E.III.4; Land Remote Sensing Policy Act, Public Law 102-555, 102nd Congress, H.R. 6133, 28 October 1992; 15 U.S.C. 5601; 106 Stat. 4163.

2 Declaration on International Cooperation in the Exploration and Use of Outer Space for the Benefit and in the Interest of all States, Taking into Particular Account the Needs of Developing Countries, UNGA Res. 51/122, of 13 December 1996; XXII-I Annals of Air and Space Law (1997), at 556; 46 Zeitschrift fur Luft- und Weltraumrecht (1997), at 236. 
in the Exploration and Use of Outer Space, including the Moon and Other Celestial Bodies, and the relevant instruments of the International Telecommunication Union.

This safety-net clause in practice is largely relevant for the space part of remote sensing activities, and hence less important for user issues. This is the consequence of the fact that international law plays its largest role in outer space where no single state can exercise comprehensive - that is territorial - jurisdiction, with the ensuing legal control over activities undertaken there. Terrestrial activities involved in remote sensing are almost by definition directly regulated by individual states; the "safety-net" of general international law would thus be far less called upon to substitute for specific rules of space law which are absent.

\subsection{Principle IV}

Remote sensing activities shall be conducted in accordance with the principles contained in article I of the Treaty on Principles Governing the Activities of States in the Exploration and Use of Outer Space, including the Moon and Other Celestial Bodies, which, in particular provides that the exploration and use of outer space shall be carried out for the benefit and in the interests of all countries, irrespective of their degree of economic or scientific development, and stipulates the principle of freedom of exploration and use of outer space on the basis of equality. These activities shall be conducted on the basis of respect for the principle of full and permanent sovereignty of all States and peoples over their own wealth and natural resources, with due regard to the rights and interests, in accordance with international law, of other States and entities under their jurisdiction. Such activities shall not be conducted in a manner detrimental to the legitimate rights and interests of the sensed State.

This Principle involves the core issue of satellite remote sensing: the dilemma between the freedom of use of outer space, in its particular manifestation of freedom of informationgathering making use of satellites, and the principle of sovereignty of states over their own territory, more in particular over their own wealth and natural resources. These two concepts collide where the "sensed state" finds itself in a situation where a "sensing state" might obtain valuable information, especially in economic terms, with regard to the territory of the "sensed state" which that state itself does not possess.

A balance has been established by the Resolution that tilts in favor of the freedom of space activities. The principle of full and permanent sovereignty, it is true, is to be respected, consequently legitimate rights and interests of the "sensed state" shall not be harmed, and the benefit and interest of all countries shall be taken into account. All this, however, does not alter the fact that the "sensed state" has no veto to prevent it from being "sensed," or even an exclusive, free, or preferential right of access to the data. This becomes especially clear when this Principle is seen in conjunction with Principles XII and XIII.

The main consequences of this Principle for users at the private level are indirect. The duty to protect legitimate interests of "sensed states" might be interpreted and implemented by individual "sensing states" through a restrictive or conditioned dissemination mechanism. On the other side, if users of remote sensing data in the course of such usage violate this Principle, to the extent it could be considered legally binding, it is the state of 
nationality or territory of operation of such users which will be held accountable at the international level under the principle of state responsibility as restated in Principle XIV.

\subsection{Principle $V$}

States carrying out remote sensing activities shall promote international co-operation in these activities. To this end, they shall make available to other States opportunities for participation therein. Such participation shall be based in each case on equitable and mutually acceptable terms.

This Principle has its relevance almost comprehensively on the public international, "interstate" level. "Duties" such as the one to promote cooperation or allow for participation in remote sensing activities are mainly of concern to states. Only to the extent that such obligations may "trickle down" to private users, e.g. through individual states providing for substantiated legal provisions affecting data dissemination, would this evaluation change.

\subsection{Principle VI}

In order to maximize the availability of benefits from remote sensing activities, States are encouraged, through agreements or other arrangements, to provide for the establishment and operation of data collecting and storage stations and processing and interpretation facilities, in particular within the framework of regional agreements or arrangements wherever feasible.

Even though the focus here is directly on data issues, in the first instance essentially the same conclusion applies as regards Principle V. The rather open-ended formulation of the Principle ("are encouraged"; "wherever feasible"), in conjunction with the principled lack of binding force, will not readily result in many states establishing relevant rules on a (private) user-level.

From a policy perspective though, this evaluation should probably take a quite different direction. Actions by states in following up on the suggestions provided by this particular Principle may have considerable consequences for the availability of data, and hence for the possibilities for disseminating and using them. In other words: any policy destined to enhance dissemination and use of remote sensing data might involve implementing measures following this Principle as a major element.

\subsection{Principle VII}

States participating in remote sensing activities shall make available technical assistance to other interested States on mutually agreed terms.

Being little more than an extension of or complement to Principle VI, the same reasoning applies to this Principle, urging the sharing of technical knowledge (in conjunction for example with Principle XIII). It might be reiterated here that "remote sensing activities," in accordance with Principle I(e), includes data dissemination activities. On the other hand, the reference to "mutually agreed terms" obviously means no specific measure of sharing of technical knowledge needs to result from application of this Principle. 


\subsection{Principle VIII}

The United Nations and the relevant agencies within the United Nations system shall promote international cooperation, including technical assistance and coordination in the area of remote sensing.

This Principle is even one step further away from the private user-level than the previous ones, in that it sketches the desired measure of involvement of the United Nations system in promoting the aims of the Resolution in rather broad and vague terms. How such a role would work in the particular user-relevant area of data dissemination, as included in the term "remote sensing," remains to be seen.

\subsection{Principle IX}

In accordance with article IV of the Convention on Registration of Objects Launched into Outer Space and article XI of the Treaty on Principles Governing the Activities of States in the Exploration and Use of Outer Space, including the Moon and Other Celestial Bodies, a State carrying out a program of remote sensing shall inform the Secretary-General of the United Nations. It shall, moreover, make available any other relevant information to the greatest extent feasible and practicable to any other State, particularly any developing country that is affected by the program, at its request.

The substance of this Principle, though largely relating to a procedural issue, has a potentially important impact on user issues especially as regards the second provision. The terminology used with regard to informing other states ("relevant information"; "to the greatest extent feasible and practicable") would still leave considerable leeway in applying it, for states that are forced or feel forced to adhere to this Principle.

The core question here is to what extent individual states, in domestically regulating dissemination and usage issues, will impose comparable duties upon disseminators and users to inform other states, thus possibly coming into conflict with industry's interests in commercial secrets and property rights protection. The provisions are directed at states themselves - although less clearly so on the second issue - but it would seem logical for a state which itself would adhere to this Principle to make its private disseminators and users adhere to it too. After all, a state's potential international responsibility would remain also for such private players (Article VI, Outer Space Treaty).

\subsection{Principle X}

Remote sensing shall promote the protection of the Earth's natural environment. To this end. States participating in remote sensing activities that have identified information in their possession that can be used to avert any phenomenon harmful to the Earth's natural environment shall disclose such information to States concerned.

The interesting issue in regard to this particular Principle is its clear moral value which, coupled with general duties of care, international co-operation and respect for benefit and interest of all countries, makes it rather difficult for states not to make even private dis- 
seminators or users adhere to it. Thus, although directed again at states, and probably even in the absence of explicit obligations on the domestic/private level for disseminators and users, neglecting these provisions in disseminating or using remote sensing data might not be legally excusable any longer.

This would also relate to the question regarding the legal consequences to be attached once the provisions of this Principle are neglected. On that point, the international responsibility of a particular state (or of some states jointly) under Article VI of the Outer Space Treaty and Principle XIV would make that state answerable to other states (e.g. the "sensed state"), while probably trying to derogate any substantive consequences through national legislative means to the relevant private entities.

\subsection{Principle XI}

Remote sensing shall promote the protection of mankind from natural disasters. To this end. States participating in remote sensing activities that have identified processed data and analyzed information in their possession that may be useful to States affected by natural disasters, or likely to be affected by impending natural disasters, shall transmit such data and information to States concerned as promptly as possible.

Principle XI largely mirrors Principle X, the former dealing with man-originated threats to the natural environment of the Earth, the latter with nature's threats against mankind. Consequently, the evaluation of Principle X largely applies here as well; for example, when it comes to the prima facie focus on states possessing data, or as regards the vagueness of terminology ("identified," "may be useful"), from which no conditions for disclosure can readily be distilled. Nevertheless, the obvious moral value of this Principle also calls for care as regards any conclusion on non-binding effects vis-à-vis private disseminators or users. One noticeable difference is that Principle XI is more detailed in explicitly applying to "processed data" in addition to "analyzed information," as opposed to mere "information."

\subsection{Principle XII}

As soon as the primary data and the processed data concerning the territory under its jurisdiction are produced, the sensed State shall have access to them on a non-discriminatory basis and on reasonable cost terms. The sensed State shall also have access to the available analyzed information concerning the territory under its jurisdiction in the possession of any State participating in remote sensing activities on the same basis and terms, particular regard being given to the needs and interests of the developing countries.

Principle XII is the second Principle dealing with the major dilemma arising from the Resolution, next to Principle IV. No veto exists for the sensed state to prevent it from being "sensed," nor an exclusive, free, or preferential right of access to the data. Rather, access is to be made available "on a non-discriminatory basis and on reasonable cost terms." In other words: for the purpose of a particular set of remote sensing data concerning its territory the "sensed state" is no different from any other state interested in such data. 
"Discrimination" is making distinctions between equal cases, i.e. cases that are not different from each other on those points that matter. But what is "equal"? What are points that matter, and what points do not? Who decides on such issues in particular cases? Thus, implementation may already be seen to take rather different forms - partly in conjunction with problems arising with regard to the threefold distinction made in Principle I. The United States for instance has restricted the application of "non-discriminatory access" to unenhanced data, for reasons of drawing a different balance between the interests of (private) entities active in the sector in commercial and trade secrets and the right of the public at large to information.

Also, the non-discrimination principle is subject to many different interpretations. For example, whether a pricing policy resulting in price differentiation for conceptually similar types of activities - because one entity would be willing to pay more than another - would be allowed is far from undisputed yet. By contrast, where public authorities cofund, subsidize, or substantively support private remote sensing activities, it seems obvious that in such a case these public authorities have a right distinct from those of others to the resulting data, as this would not be tantamount to "(dealing unequally with) equal cases."

Similarly, it has not been considered "discrimination" when data disseminators - especially governments - apply different prices to scientific and/or non-commercial users on the one hand, and commercial users on the other. Consequently, on a national or regional level distinctions are usually made between users from the scientific, educational or other evidently public sectors (which usually have to pay nothing or only cost-based fees) and commercial users (who have to pay substantially higher, essentially commercial fees). However, due to the vagueness at the level of the United Nations Principles, national and regional policy implementation of this principle has taken place in many different ways.

The difference between primary and processed data on the one hand and analyzed information on the other hand further exacerbates the situation. As to the first, a "sensed state" will only have access to the data concerning its territory if the "sensing state" or any entity for whom it is responsible is interested in marketing and selling those data - and then, of course, at the same ("non-discriminatory") price and other conditions attached. As to the second, the - already vague - right of access "as soon as" data have been produced is missing; no time limit is provided for at all. Moreover, a right of non-discriminatory access for a "sensed state" exists only with regard to analyzed information in the hands of a "sensing state" - not, therefore, in the hands of any entity for whom it is internationally responsible. At least, that has been the interpretation to date of experts, states and international organizations alike.

Because of the importance of the non-discriminatory principle, a detailed consideration of the issues is given in the next chapter.

\subsection{Principle XIII}

To promote and intensify international co-operation, especially with regard to the needs of developing countries, a State carrying out remote sensing of the Earth from space shall, upon request, enter into consultations with a State whose territory is sensed in order to make available opportunities for participation and enhance the mutual benefits to be derived therefrom. 
Principle XIII, further to Principle XII, once again makes clear that there is no preferential treatment of a "sensed state" with regard to the data concerning its territory. If consultations do not lead to a negotiated outcome acceptable to both parties, there would be no "obligation" (to the extent of course that the Resolution is able to impose obligations in the first place) for the "sensing state" to treat the "sensed state" any better than it does other states interested in these data. Furthermore, no conditions ratione temporae are provided to which any consultation process should conform. Substantial effects on user issues therefore seem to be remote at this juncture.

\subsection{Principle XIV}

In compliance with article VI of the Treaty on Principles Governing the Activities of States in the Exploration and Use of Outer Space, including the Moon and Other Celestial Bodies, States operating remote sensing satellites shall bear international responsibility for their activities and assure that such activities are conducted in accordance with the provisions of the Treaty and the norms of international law, irrespective of whether such activities are carried out by governmental or non-governmental entities or through international organizations to which such States are parties. This principle is without prejudice to the applicability of the norms of international law on State responsibility for remote sensing activities.

This Principle, next to the cluster of Principles IV, XII, and XIII as dealing with the fundamental dilemma underlying satellite remote sensing, is the other core Principle of the Resolution, since it deals with the issue of State responsibility in the particular case of satellite remote sensing activities.

As Principle XIV itself states, it also includes non-governmental entities within the scope of the Resolution and the concept of international responsibility. The legitimacy of private involvement in any aspect of space remote sensing activities is thereby confirmed. The Principle refers explicitly to Article VI of the Outer Space Treaty, and is "without prejudice to the applicability of the norms of international law on State responsibility for remote sensing activities." Consequently, under this Principle a state should be held responsible on the international level for those private entities undertaking remote sensing activities which either operate from its territory or have its nationality (through incorporation), whose activities are in consequence - for the purpose of the Resolution - equated to that state's "own" activities.

Thus, individual states would be inclined in relevant cases not only themselves to adhere to the principles contained in the Resolution - at least to the extent they might be considered as having customary legal force - but also to make legally certain that they can control those private entities involved for which they might be held accountable those with their respective nationalities or operating from their respective territories. In the absence, however, of such domestic legislative measures, it might be difficult not only to derive direct guidance from the Principles as to which kind of activities are not allowed, but also to discern what legal consequences would or should apply once such a situation arises or is seen to have arisen.

Even more poignant, however, for the present purpose is the fact that state responsibility under Article VI of the Outer Space Treaty relates to "national activities in outer space." 
Consequently, not only private user activities but also private disseminator activities would not be covered by at least this version of state responsibility, although the Resolution itself - referring to states "operating remote sensing satellites" - is less unequivocal on this. Conversely, general state responsibility does only require "due care" from states vis-à-vis private activities emanating from within their respective jurisdictions. As private disseminator activities would thus tend to lead to state responsibility on the international level less directly than when it comes to space activities proper, states would have considerably less inclination to arrange for sufficient and appropriate domestic regulation.

Finally it should be noted that the issue of liability - the special form of accountability which deals with damage being caused as a consequence of space activities - is not touched upon in the Resolution. This means simply that the liability rules applicable to all space activities by virtue of - and under the terms of - Article VII of the Outer Space Treaty and the Liability Convention continue to apply to remote sensing activities. In other words: if satellite Earth observation activities cause damage, the launching state(s) is (are) liable. Such liability would be unlimited and, as far as damage suffered on the ground is concerned, does not require proof of fault in order to be accepted. A major restriction, however, as regards data dissemination and usage issues relates to the fact that such liability applies to damage "caused by a space object," as opposed for example to "by wrong data": usually, physical impact by the satellite concerned is even considered requisite.

\subsection{Principle $X V$}

Any dispute resulting from the application of these principles shall be resolved through the established procedures for the peaceful settlement of disputes.

The impact of this Principle on (private) user issues would be quite remote. The whole Resolution being state-oriented, the "established procedures" referred to are state-to-state procedures such as diplomatic negotiation, mediation, conciliation, arbitration, and recourse to an international tribunal or court having jurisdiction. These established procedures are the same as those generally provided by international law, inter alia as mentioned by the United Nations Charter. For private entities involved in the space part of remote sensing operations, the consequences of this state-oriented dispute settlement mechanism might be quite severe, since it might preclude in many ways solutions to conflicts that are fair to private parties.

\section{Conclusions}

While the UN Resolution on remote sensing was adopted by consensus, basically it does not infringe upon the freedom to undertake remote sensing activities from outer space and undertake downstream activities such as data dissemination. Little is provided by way of international legal obligations that are potentially relevant for private entities undertaking these activities, involving specifically private disseminators, let alone private users. The only specific and substantive provision at least potentially relevant from this point of view is the non-discrimination requirement. It does, however, "trickle down" to private entities in a far from unequivocal fashion - if at all. 
As a consequence, individual states enjoy a large degree of discretion with respect to the contents of national space legislation on this issue, whether in regard to their own governmental activities in this field, or those of non-governmental entities falling under their jurisdiction and international responsibility. Mutatis mutandis, the same applies to international organizations creating their "own" legal framework as regards the dissemination and use of the data resulting from their own operations. Also, the sometimes complex structure of entities involved in particular aspects of remote sensing activities, down to data distribution, does not change this fundamental conclusion. It merely results in confronting the users with a number of relevant parameters handed down the chain through the mechanism of contracts, referring back to upstream contractual or other obligations.

A major issue in satellite remote sensing from the user's point of view is that of intellectual property rights protection. Intellectual property rights (whether copyright, database, or other) present an outstanding means for the upstream entities to control dissemination, distribution, and ultimately also usage of the data resulting from their activities. Intellectual property rights, however, in line with the aforementioned are not dealt with as such by the UN Resolution. Any legal parameters confronting users on this issue stem exclusively either from national legislation or from special international frameworks (ESA with regard to its own remote sensing data; the European Community in view of harmonization of national laws for purposes of the Internal Market).

The basic choice in this regard confronting any entity having the option to use intellectual property rights, from the user perspective at least, concerns widespread usage versus optimum protection of property interests. Widespread usage is, indeed, in the interests of creating and benefiting market development, through economies of scale and familiarity of use. It is also the basic consequence of adhering to the UN Resolution's most substantive provisions on non-discriminatory access in the benefit and interests of all countries, and the required efforts at international co-operation.

Adversely, however, in practice those regulatory entities interposing themselves between the Resolution and the users - notably the individual states (and the European Community) with their, largely still discretionary, legislative powers, and those international organizations such as ESA and EUMETSAT which themselves are active in this field - also try to protect their interests, in commercial but also defense- and security-related terms, by establishing a number of conditions to which access to data is subject. To what extent such conditions would be akin to violations of the non-discriminatory access principle, is and remains subject to debate. 